\title{
Cervantes ante la palabra lírica: el Quijote
}

\author{
FERNANDO ROMO FEITO*
}

\section{PRELIMINARES}

Si Modernidad implica centralidad del sujeto, y Petrarca, en cuya estela poética se sitúan Garcilaso y el propio Cervantes, ha creado un héroe nuevo, el héroe que siente, está justificado tratar de la poesía de Cervantes a propósito de la invención de la Modernidad. Ya nadie discute hoy si Cervantes era o no poeta, ni si era mal poeta. El momento decisivo lo marca la edición de poesía cervantina de Ricardo Rojas $(1916)^{1}$, cuando se refiere a "don Martín Fernández de Navarrete (1765-1844), uno de los primeros cervantistas que consideró a Cervantes como autor de poesías" (Rojas, 1916: XXI), quien "marcó, desde 1819, el canon con que se ha venido juzgando a Cervantes" (Rojas, 1916: XCI). Canon que Rojas identifica así: "Él consagró el error de considerar los versos de Cervantes en contraste con la gloria de su prosa, cuando debió juzgarlos solamente en comparación con los otros versos de su época. Él aseguró que Cervantes había renunciado al verso en la madurez y atribuyó esta claudicación supuesta al influjo de la crítica" (Rojas, 1916: XXI). Tras el pertinente ajuste de cuentas con lo anterior, el segundo momento de la crítica, a partir de Rojas, se esfuerza en comprender a Cervantes en su singularidad (lo que no quita para la disparidad valorativa, que se puede seguir cómodamente en la anotación de la edición de V. Gaos, 1973-1981); así proceden poetas de la Generación del 27 como Cernuda o Diego. Hoy, el

* Universidad de Vigo

1. Aunque ya en 1873 lo había reivindicado Menéndez Pelayo en el Ateneo de Barcelona, en "Cervantes considerado como poeta", incluido hoy en el tomo VI de la edición nacional de Obras Completas (Estudios y discursos de crítica histórica y literaria I). 
canon interpretativo da por supuesto que Cervantes es poeta, y un gran poeta, diferente, eso sí, a los mayores de sus contemporáneos.

La bibliografía sobre la poesía de Cervantes ha crecido de forma exponencial, aunque a un ritmo menor que la consagrada a los demás géneros que cultivó (seguimos sin un libro global al respecto). Y en el conjunto de esa bibliografía, cabe registrar unos cuantos títulos centrados en los poemas incluidos en el Quijote, de 1605 y de 1615: como mínimo, los de Amorós (1981); Jauralde Pou (1987-1988); Garrote Bernal (1996); Fernández García (2001); Montero Reguera (2004); Luján Atienza (2008), cuyo número aumenta enormemente si se les añade las reflexiones dedicadas al Quijote en estudios generales de la poesía cervantina, así como los trabajos dedicados a poemas sueltos (Romo, 2001: 1063-1088) ${ }^{2}$. Desde luego, el avance en lo que se llama "contextualización" ha sido enorme; quizá no tan grande en la definición de lo que distingue esta poesía frente a las de sus contemporáneos, es decir, en la interpretación respecto del conjunto de la obra del autor y de la poesía de su época desde un punto de vista estético. Aquí prescindiremos de las discusiones cervantinas sobre la naturaleza de la poesía.

J. Manuel Blecua (1947) distinguió en 1947 tres etapas en la poesía de Cervantes: hasta 1585 , más bien renacentista; de 1585 a 1605, de innovación barroca; y de 1605 a 1616. Y Elías Rivers (1983: 570): “Entre 1590 y 1600 parece que Cervantes mismo sufrió una crisis espiritual, literaria y social, después de la cual no le bastaban ya los ideales clásicos que representaba la poesía garcilasiana". Y en efecto, se ha impuesto la idea de cifrar un cambio en la poesía cervantina a la altura de los sonetos A la entrada del Duque de Medina en Cádiz (1596) y Al túmulo del Rey Felipe II en Sevilla (1598). De modo que los poemas de los dos Quijotes corresponderían a esa desengañada región central de su producción, anterior al Persiles. Lo que lleva aneja la idea de que toda la poesía cervantina inserta en su obra posterior a La Galatea se opondría en bloque a ésta, la más claramente renacentista, que quería ser una égloga y ser aceptada como poesía trascendiendo el contraste prosa/verso; así como que, dentro del segundo bloque, a su vez, habría que diferenciar un cambio, se supone que de nuevo idealista, que corresponde al Persiles y Segismunda. Esta interpretación da por buena, sin más, la lectura alegórica del Persiles. Pero si se lee con Isabel Lozano (1998) el Persiles como una variación sobre la novela de aventuras, y en consecuencia, como ampliación del ámbito del realismo por presentar lo maravilloso como real, la cosa varía. Pues parece entonces más ajustado acordarse de la contraposición entre novela y romance, propuesta por Edward Riley (1973), que viene a representar el equivalente al contraste entre realismo e idealismo, merced al cual se justifican los supuestos vaivenes en la producción del alcalaíno, lo que se complementa con su perfil

2. Allí repasé en general la bibliografía cervantina al respecto; las referencias se deben completar ahora con las de Montero Reguera, 2011. Prescindo de algunas cosas dichas después que poco afectaban al problema del Quijote. 
como escritor experimental, asentado por Riley desde su ya clásica Teoría de la novela en Cervantes (1962).

1. Un inventario problemático. Lo que importa aquí es que el citado contraste, como veremos, ayuda a explicarse la presencia de los poemas del Quijote, sobre todo en el de 1605. Tenemos un útil inventario de estos en Montero Reguera (2004), sin más que advertir que los dos poemas que llevan los números 30 ("Marinero soy de amor") y 31 ("Dulce esperanza mía") no se encuentran en I, 44 sino en I, $43^{3}$. Claro que, como señala Montero, los compuestos por don Quijote en I, 26, o por los Académicos de Argamasilla en I, 52, son — en la ficción - muchos más, pero hay que contar los que podemos leer, no los que según el narrador se perdieron. El inventario de Montero da un total de 38 poemas para 1605 y 40 para 1615 , en total 78, que no coincide con los 49 (números 81 a 151) registrados en la ed. de Gaos ${ }^{4}$ (distribuidos entre el Quijote de 1605, 34 poemas, y el de 1615, 15), ni con otras cuentas parciales (la de Amorós). Por otra parte, si se acude al apéndice de Alonso Asenjo (2000: 63-65), que lista las "citas, alusiones o reminiscencias de romances" con exclusión de los originales de Cervantes, hay 25 entradas para 1605 y 47 para 1615, total 77 solo de romances. Disparidades que se explican porque Gaos considera sólo poemas completos, mientras que Montero añade fragmentos y Alonso incorpora las alusiones insertas en la prosa, sin los romances originales. Como sea, queda de relieve la abundante presencia en obra no poética de la poesía de la época, con ventaja, si nos fijamos sólo en lo cuantitativo, para el romance, y en segundo lugar, para el soneto, y en proporción cronológica inversa: 17 sonetos en 1605 y 2 en 1615; 7 romances en 1605 frente a 15 en 1615; y en conjunto, 16 poemas de arte menor en 1605 frente a 24 en 1615. Naturalmente, es tentador concluir que se da una evolución en el sentido del progresivo abandono del endecasílabo y superior frecuencia de versos "españoles", criterio que siguió Canavaggio para datar el teatro cervantino. Sin embargo, el tipo más frecuente en La entretenida, probablemente la más tardía de las comedias cervantinas, es precisamente el soneto, eso sí, burlesco, y en el Persiles, de nuevo predomina el soneto, aunque ahora son serios, digámoslo así. La única conclusión posible resulta, en consecuencia, que solo la métrica, al margen del género y del principio retórico y poético del decoro, no es criterio definitorio de evolución alguna.

2. Verso y prosa. En cuanto al problema de la novedad de tanto verso en prosa no pastoril, en trabajo ya clásico de carácter general apuntó Ynduráin (1985: 227) que no escasean en la época los títulos de narrativa ilustrados por poemas: La pícara Justina, La Garduña de Sevilla; y menciona además a Antonio Enríquez Gómez y Tirso de Molina, aún antes de llegar a La Dorotea (1632) de Lope. Pero Montero (2004: 39-40) nota que las fechas de las obras

3. De acuerdo con la edición dirigida por F. Rico en dos volúmenes, Madrid, Círculo de Lectores/ Galaxia Gutemberg y Centro para la Edición de los Clásicos Españoles, 2005, por la que cito.

4. También en ésta hay una errata, pues titula “Ovillejos de don Quijote” los que no canta él sino Cardenio en I, 27. 
citadas son posteriores a las del Quijote, y de géneros, como la novela corta, al margen de la caballeresca, que, precisamente, muy pocas veces incluye versos (una canción en Amadís de Gaula II, 54). De donde infiere, y me parece conclusión razonable, que estamos ante "un elemento de cierta novedad" que atribuye a géneros diferentes del modelo caballeresco, en concreto a la novela corta en la que Cervantes es maestro - con las Ejemplares - y al propio romancero: "En cierta medida, de la poesía - del romancero, especialmente- y de la novela corta surge el Quijote (pienso sobre todo en la primera parte)". Conclusión que se subordina a la más general de que "Cervantes utiliza la poesía como elemento auxiliar para la construcción de una obra literaria de radical novedad en la época, de la misma manera que acude a otros saberes y elementos: la erudición, la geografía, la experiencia vital, etc." (Montero, 2004: 49-50).

3. Poemas que enmarcan la Primera Parte. Pero acerquémonos ya a los poemas en sí, empezando por los de la primera parte. Desde luego la fórmula realismo/idealismo sin matices amenaza engañarnos, sobre todo si identificamos su segundo término con la forma soneto. El soneto llega a constituir un verdadero género poético en el Renacimiento, pero un género que sufrirá también la erosión que supone la parodia y la burla. Todos estamos de acuerdo en considerar el Quijote de 1605 como parodia de los libros de caballerías o libro de caballerías burlesco, que viene a ser lo mismo 5 . En el prólogo, el autor asegura al "desocupado lector" que "sólo quisiera dártela monda y desnuda, sin el ornato de prólogo, ni de la innumerabilidad y catálogo de los acostumbrados sonetos, epigramas y elogios que al principio de los libros suelen ponerse". Sea cierto o no que Cervantes andaba por Valladolid pidiendo en vano que se los compusiesen ${ }^{6}$, bastará con que su amigo ficticio le aconseje escribirlos y atribuirlos a quien le parezca, para que, contradiciéndose alegremente, anteponga a su libro hasta diez poemas dedicados sucesivamente al propio libro, a don Quijote, a Dulcinea, a Sancho, a Rocinante, y otra vez a don Quijote, para terminar con el diálogo equino entre Babieca y Rocinante. Orden lógico, pues por el libro - y por los libros, en general- existen los personajes, y degradante, pues remata en ver a amo y criado a través de los ojos del caballo y motejarlos de tan rocines como éste. ¿Los autores? Cervantes se ha divertido en prohijárselos a Urganda la Desconocida, personaje de Amadís de Gaula; al propio Amadís; a don Belianís; a Oriana, también personaje de Amadís; a Gandalín, escudero de éste; al Donoso, personaje de invención propia; a Orlando, que nos hace pensar en Ariosto; al Caballero del Febo; a Solisdán, que no sabemos quién es; y a Babieca y Rocinante. Salvo el Donoso y Solisdán, son todos personajes representativos de ese mundo que se trata de parodiar,

5. La segunda definición es de D. Eisenberg (1987). La diferencia entre una y otra estriba en que la de Eisenberg se mueve en el ámbito de la Filología, más bien reconstructivo, mientras que la primera apela a un concepto, el de parodia, de definición genérica y estética.

6. Como sabemos, estos poemas pueden verse como un episodio de la enemistad literaria entre Cervantes y Lope, aspecto del que no nos vamos a ocupar aquí. Puede verse la síntesis de J. Montero Reguera (1999). 
un pasado ficticio juzgando al presente y por él convocado. Como han notado cuantos se han acercado al problema ${ }^{7}$, a excepción de las décimas de cabo roto de Urganda ${ }^{8}$, que aconsejan al autor de una forma concordante con la del amigo del prólogo, estos protagonistas de libros cuya autoridad el autor y su amigo han afirmado pretender derribar, si alaban las hazañas de don Quijote por superiores a las suyas, le están haciendo más loco aún que ellos mismos. Estamos en la figura del encomio paradójico, de antiquísima tradición retórica, con la diferencia de que, mientras que los rétores que alababan a una mosca no la tomaban en serio, no cabe duda de que Cervantes no desprecia su libro ni mucho menos.

¿Cómo caracterizar el estilo general de los poemas? La construcción retórica y el tono solemne son los propios de los escritos en serio. Por ejemplo, el soneto del Monicongo se basa en el mismo esquema retórico - la anáfora continuada hasta alcanzar un cierre rotundo- que el dedicado a la muerte de Fernando de Herrera: "El que.../el que.../el que.../ yace debajo desta losa fría”. De modo semejante los demás. No se debería, pues, hablar de antipetrarquismo ${ }^{9}$; sí, en cambio, de sustitución de la amargura por el humor; a diferencia de lo que ocurre en la tradición reciente, italiana y española, la misoginia y la obscenidad no son aquí centrales, aunque no falten; se hace un uso comedido del léxico de germanía. Por otra parte, en el aspecto métrico, las rimas tampoco sufren de la habitual facilidad excesiva que se suele achacar a Cervantes: además del cabo roto, los sonetos de Oriana y don Belianís recurren a la rima en -ote, de efecto humorístico por asociación con el nombre del héroe. Y no se trata sólo de recursos formales. De hecho confluyen en los poemas, tres tradiciones: la clásica humanística; la popular y carnavalesca; y la invectiva personal (Laskier Martin, 1990: 349). Lo que se aprecia con especial nitidez en el diálogo entre Babieca y Rocinante, el mejor de los poemas citados (del que es imposible olvidar aquello del "Metafísico estáis —Es que no como", aclarado por F. Rico, 1997), en el que se muestra el mundo al revés en que los animales hablan, sin olvidar antecedentes clásicos, por ejemplo, el Asno de oro.

Cuando el lector alcanza el capítulo 52, último de la primera parte, se encuentra con un efecto de suspensión paralelo al de I, 8, pero más radical: le es imposible conocer los hechos de la tercera salida del héroe y ha de contentarse con la lectura de algunos epitafios y elogios a don Quijote, de cuya muerte nada se ha dicho, los que se han podido leer de entre los contenidos en una caja de plomo aportada por un antiguo médico. Por medio de este artificio introduce Cervantes una fantasmal Academia de la Argamasilla (más

7. Comentarios detallados en P. L. Ullman (1961-1962), cuyo concepto central es el de perspectivismo; F. Márquez Villanueva (1987), es el trabajo más completo; añádase A. Laskier Martin (1990).

8. Procedimiento burlesco al parecer inventado por Alonso Álvarez de Soria, según advierten en su edición F. Sevilla y A. Rey Hazas (1993 I: 27 n. 48), que se pone de moda en el s. XVII. Cervantes lo utiliza más veces, por ejemplo, por boca del Donoso. Debe verse J. Lara Garrido (1987).

9. Sigo a partir de aquí los rasgos generales definidos por A. Laskier Martín (1990), para caracterizar la poesía burlesca de Cervantes en conjunto, pero adaptándolos al caso. 
dura que la argamasa), parodia parece que no de las italianas pero sin duda sí de las españolas, bien conocidas suyas. Todos los poetas, de nombre grotesco, son ahora pura invención libre, sin más antecedente que la libre imaginación del autor ${ }^{10}$ : el Monicongo, el Paniaguado, el Caprichoso, el Burlador, el Cachidiablo y el Tiquitoc, que dedican cuatro sonetos y dos octavillas (dobles redondillas) a la memoria respectivamente de don Quijote, Dulcinea, Rocinante, Sancho, y de nuevo don Quijote y Dulcinea.

Estos poemas responden a los del principio, y ya desde el artículo de Ullman se los considera un marco - de cornice, recordando el término italiano, habla Garrote Bernal (1996) — para la narración de las hazañas de don Quijote. Pero estamos ahora ante epitafios, versos de circunstancias obra de hombres sedentarios, subrayan Ullman (1961-1962) y Márquez Villanueva, que mientras que los autores de los preliminares alguna vez tuvieron cierta clase de vida, éstos sólo muerte; incluso dan por muertos a personajes cuya tercera salida aún esperamos. Laskier Martín se ha fijado más bien en que, frente a la burlona ironía de los preliminares, los epitafios entran de lleno en lo insultante, y así don Quijote es "calvatrueno" y "anduvo errando"; Dulcinea, "de rostro amondongado" y "castiza ralea"; Sancho Panza, "manso, borrico y majadero". Lo que no impide que encontremos versos como "y al fin paráis en sombra, en humo, en sueño" (v. 14 del Burlador), que evoca a Góngora y contrasta con el tono general. Es también idea de Márquez Villanueva la de interpretar en conjunto la primera parte del Quijote como una academia presidida por el propio don Quijote: los sonetos burlescos iniciales funcionarían como el encomio, el texto constituiría la sesión de la academia —y qué sesión-, y los epitafios formarían el vejamen. Asistentes, por tanto, somos todos los lectores. No sé si no habrá algo de sobreinterpretación en ello, puesto que la experiencia de lector me dice que en cuanto aparece don Quijote en escena nos hace olvidar los preliminares, cuyo recuerdo sólo resurge al final, justamente en la Academia. Pero desde luego, el texto no lo contradice. Lo que está claro es que desde el principio los sonetos nos introducen de lleno en la parodia que es el Quijote, son parte de la novela, puesto que, como ya vio Bajtin (1989: 421), "no tenemos ante nosotros un soneto, sino la imagen del soneto". La parodia es posible porque acoge en sí un discurso primero, la forma soneto - como la caballeresca en su conjunto-, y ridiculiza en ella lo que aprecia caduco. Puede servirse de esquemas retóricos propios de sonetos serios, o acordarse de versos no menos serios, remedar el tono solemne del elogio o del epitafio y hacerlos servir para contenidos risibles. Así se operaba ya en la poesía una crítica de lo elevado muerto paralela a la que en la prosa abriría camino al realismo. Pues no en vano la esencia de éste consiste en reconocer la diversidad social, cosa imposible para el mundo señorial de la caballeresca.

10. Pero véanse las minuciosas y convincentes conjeturas de Márquez Villanueva (1987), en cuanto a posibles colaboradores y blancos de las invectivas de Cervantes. Sobre el epitafio en general: J. Montero Reguera (2011b). 
4. El Quijote y el Romancero. Una vez dentro del marco, conviene que nos refiramos primero en conjunto al problema de los romances. Ya hemos aludido a la razonable conjetura de que el romancero constituyera una de las fuentes de inspiración del Quijote. Realmente, romances originales cervantinos en la obra sólo hay dos, el que canta Antonio (I, 11) y el de don Luis (I, 43), que habría que clasificar como "nuevos"; sin embargo, si se examinan las citas más o menos amplias de romances tradicionales, más o menos modificados, aparecen en I, 2; I, 5; I, 911; I, 13; I, 49 (los mismos versos citados en I, 9), desde luego sin discriminar entre nuevos y viejos. Pero si acudimos a la relación de Altamirano (1997) y sobre todo a los índices de citas, alusiones o reminiscencias de Alonso Asenjo (2000), el número total de éstas se eleva, sólo para 1605, a 25. Pudiera pensarse que ello se vincula a la conocida teoría de que se hubiera originado el Quijote por expansión de una novela corta, similar a las Ejemplares, cuyo protagonista hubiera enloquecido a fuerza de leer romances, en la que influiría además el Entremés de los romances (caso de ser anterior, claro está). No es así, puesto que se registran en la segunda parte no menos de 47 alusiones. Hay para ello razones que parecen convincentes: el mundo de los romances y el de las caballerías es, para el público del s. XVI, el mismo que se trata de atacar, "el de la historia o historias de caballeros, de amores y aventuras más o menos verídicas o fantásticas" (Alonso Asenjo, 1997: 26). Comparten, en una palabra, un mismo orbe estético, el de la aventura heroica. No deberíamos olvidar, además, que por lo general los romances se cantaban, lo que contribuiría a su difusión. De hecho, cuando don Quijote define su función: "Mis arreos son las armas,/ mi descanso el pelear" (I, 2), el ventero le responde en el acto parafraseando el resto. Las funciones que Altamirano y Alonso Asenjo han aislado vienen a coincidir: en primer lugar, don Quijote imita a los héroes del romancero, baste recordar los citados versos "De los que dicen las gentes/ que van a sus aventuras", repetidos además en dos ocasiones, I, 9 y I, 49, es decir, al principio y al final de esta parte, la última citados por don Quijote para definirse a sí mismo. Pero además inspiran episodios, como el de Cardenio en Sierra Morena, basado según Menéndez Pidal en Por unos puertos arriba, de Juan del Encina; o bien iluminan situaciones, como cuando en I, 5 recuerda la historia del Marqués de Mantua; sin que falten los efectos cómicos: el «val de las estacas», que ironiza en I, 17 la situación de Sancho después del encuentro con los yangüeses; ni la incorporación fraseológica. No hace falta añadir más ejemplos, que menudean a lo largo de las dos partes del Quijote, y vienen a confirmar la tesis del romancero como fuente de inspiración ${ }^{12}$.

11. Pues los versos "De los que dicen las gentes/ que van a sus aventuras" son sin duda de romance.

12. Lo que no es incompatible con que el romancero, durante el reinado de Felipe II, no fuera valorado muy altamente, como quiere M. Chevalier (1990). Ello casa muy bien con que los use don Quijote o bien personajes bajos; no me parece contraargumento que también los empleen los duques en la segunda parte, pues a estos se los moteja de tontos (II, 70) y se muestran de hecho atraídos por 
5. Poemas en el Quijote. Refirámonos ahora a los demás poemas, en los que entrarán los dos romances originales de Cervantes. En primer lugar, en cuanto a la disposición, no parece caprichosa, sino que se rige según un patrón que combina paralelismo y contraste. De paralelismo se puede hablar en cuanto que los poemas aparecen casi siempre por pares en relación con los personajes: dos son los sonetos de Cardenio (I, 23; I, 27), aunque si se piensa en I, 27 por separado los dos poemas son ovillejo y soneto; dos los poemas de Lotario en I, 33 (una octava real traducida de Tansillo y tres redondillas); y de nuevo dos sonetos en I, 34; dos los sonetos de D. Pedro de Aguilar (I, 40); dos los poemas cantados por D. Luis (I, 43), el uno un romance, el otro, una oda en estrofas aliradas. Sólo escapa a esta regla la copla de arte real que dice el narrador en I, 33. Pero también hay contraste, en cuanto, perteneciendo ambos al ámbito pastoril, el romance rústico de Antonio contrasta en tono con la cultísima "Canción desesperada" (I, 14); o en cuanto que a la letrilla en coplas reales de D. Quijote (I, 26) se enfrentan los ovillejos de Cardenio del mismo capítulo y se intercalan entre los dos sonetos de este último. Se trata pues, parece, de una disposición cuidada, ya se explique por el deseo de unidad en la variedad, o por influjo de los mecanismos compositivos propios de la oralidad (Martín Morán, 1997).

¿Cuáles son las regiones de la imaginación, por recordar una expresión de Martínez Bonati (1994), o, si se prefiere, los mundos estéticos a que corresponden estos poemas? El romance de Antonio (I, 11), la canción de Grisóstomo (I, 14) y el epitafio de Ambrosio (I, 14), y las coplas de D. Quijote $(\mathrm{I}, 26)$ evocan tres posibilidades distintas dentro del mundo del idilio pastoril: realismo, patetismo, burla; los sonetos de D. Pedro de Aguilar, que constituyen auténticos epitafios serios frente a los burlescos de los Académicos de la Argamasilla, son propios de la aventura heroica en el mundo real; el resto pertenecen al patetismo amoroso.

Problema general para la apreciación de esta poesía es el de la enunciación, que se relaciona con la idea que nos hacemos hoy de la palabra lírica ${ }^{13}$ : textos más bien breves, preferentemente en verso, que presentan instantes de la vida sentimental —instantes que parecen eternos, fuera del tiempo - de un héroe al que tendemos a identificar con el autor. Es un biografismo concentrado, porque el poema no deja espacio para un acabamiento más preciso del personaje, que le permita independizarse; por otra parte, tampoco es necesario ya que el autor domina por completo a su héroe. Pero aunque este parezca cantar

completo al mundo de nuestros héroes. Alonso Asenjo, que discute a Chevalier, deja para otra ocasión una cuestión que, en efecto, merece más detenimiento.

13. Para esta teoría de la lírica, L. Beltrán (2002). Un panorama de conjunto de la teoría de la lírica en el Renacimiento en Mª J. Vega Ramos, C. Esteve (eds.) (2004). Si se quiere enmarcar históricamente la poesía cervantina, debe verse J. Lara Garrido (1997), que no sólo esboza una historia sino imprescindibles reflexiones metodólogicas. Observación suya es la del valor de la poesía cervantina en tanto que atalaya del estado de la de su tiempo. Lo que sintetiza las contradicciones notadas: serio/ lúdico; cantado/leído (es ahora, en torno a 1600, cuando se empiezan a imprimir colecciones); unos poetas mienten (el Caballero del Bosque)/ otros dicen la verdad (Lotario). 
en soledad, necesita — como dice Bajtin — de la calidez de un coro, que por ejemplo en Petrarca está siempre presente: "Voi ch'ascoltate in rime sparse il suono" (Canzoniere I, 1). Un coro que acepte la autoridad de sus palabras hasta el extremo de identificarse con ellas porque dicen con superior belleza lo que él mismo siente. El ritmo expresa la voz con que se debe entonar el poema y es parte esencial de su belleza.

Era conveniente la anterior digresión para explicarnos mejor el efecto de unos poemas siempre atribuidos a autores interpuestos, lo que justifica aquella reflexión de Gerardo Diego de que parece que Cervantes "se traduce a sí mismo", o la de Blecua de que hablan a "media voz". Ocurría, ya lo hemos visto, con los "deliberadamente malos"14 que enmarcan el Quijote de 1605, pero resulta más notorio en los insertos en la narración. Nada de confesionalismo, pues, en contra de la idea romántica que nos es tan familiar, sino adecuación a las circunstancias y al personaje, de acuerdo con el clásico principio del decoro.

En el Renacimiento, la poesía, se ha podido decir, además de textos es una práctica de "clase": Garcilaso "fue muy diestro en música, y en la vihuela y harpa con mucha ventaja", la poesía se canta más que se lee, y los libros de música garantizan la extensión del petrarquismo por toda Europa (Vega Ramos, 2004: 31 ss). El Quijote se muestra en el filo entre el ideal del cortesano y el homo typographicus, como dice Chevalier. Frente a La Galatea, en la que preferentemente se canta, ahora los poemas se leen (es una forma de recordar o anticipar personajes), se dicen, o se recuerdan, aunque alguna vez también se canten. Y todos son o pueden ser poetas, hasta Sancho se lo propone en II, 67 (Jauralde Pou, 1987-1988: 48 ss), aunque la poesía seria sea patrimonio de los caballeros.

6. Poemas pastoriles. Con estas advertencias previas, acerquémonos a los poemas que corresponden a la idílica estética pastoril, tal vez la mayor utopía del Renacimiento. Son el romance de Antonio (I, 11), la Canción desesperada (I, 14), y la letrilla de don Quijote (I, 26). Se da el caso de que la Canción desesperada, la más fiel al paradigma de La Galatea, se lee, mientras que es Antonio el que canta su rústico romance. Y frente a la unanimidad coral esperable, llama la atención el contexto ${ }^{15}$ polémico en que se produce y se recibe el canto. Los cabreros se ven obligados a justificar el romance de Antonio: "Porque vea este señor huésped que tenemos que también por los montes y selvas hay quien sepa de música" (I, 11). Para el narrador estará claro lo contrario: "Aunque suele decirse que por las selvas y campos se hallan pastores de voces estremadas, más son encarecimientos de poetas que verdades; y más cuando advirtieron que lo que oían cantar eran versos, no de rústicos ganaderos, sino

14. Esta sabia reflexión, con la que Márquez Villanueva (op. cit.) empieza su importante artículo, fue formulada por primera vez en diversas ocasiones por Diego Clemencín, y se ha repetido luego otras muchas veces.

15. P. Ramírez (1995) se ha ocupado de este asunto en el conjunto de la obra cervantina. En él coinciden cuantos se acercan a su lírica. 
de discretos cortesanos" (I, 27). De hecho, el rústico Antonio ni siquiera es autor de sus versos - se los escribió un beneficiado - que a Sancho le dan sueño; el cura y el barbero pronto advierten en I, 27 que oyen versos de un discreto cortesano - los ovillejos de Cardenio - no de ganaderos. En parecido caso está Grisóstomo, "famoso pastor estudiante", es decir, pseudo pastor, que sí es autor de su canción; sin embargo, con él de cuerpo presente, "el que la leyó dijo que no le parecía que conformaba con la relación que él había oído del recato y bondad de Marcela" (I, 14), y Ambrosio ha de defender al difunto. Todavía Marcela discutirá el mensaje de Grisóstomo, para verse a su vez replicada por el epitafio de Ambrosio. Este problematismo enunciativo corresponde muy bien a la confrontación del ideal arcádico con el campo real, que opera desde que don Quijote pronuncia su discurso de la edad de oro ante los cabreros, con tasajo, bellotas y un queso "más duro que si fuera hecho de argamasa" (I, 11). A la "escusable arenga" de la que los cabreros no entienden una palabra, responden estos invitando a cantar al son de un rabel -no arpa, viola, ni vihuela - al zagal, enamorado y alfabetizado, pero incapaz de componer. El romance responde a un tipo ya estudiado por Menéndez Pidal, rústico más que pastoril. Correcto aunque no escaso en vulgarismos, que lo colorean de rusticidad, no expresa ningún amor imposible ni despechado, sino que requiere de amores a Olalla cara al honesto fin del matrimonio, lo cual, la verdad, no me parece que tenga nada de específicamente erasmista, o no más de erasmista que de tridentino ${ }^{16}$. Porque la afirmación de acabar casado o capuchino, se puede ver como hipérbole humorística: al fin, el romance lo ha compuesto el beneficiado, pero debe haberlo hecho conforme al decoro, tal que lo pueda cantar Antonio de forma convincente.

Mucha más atención ha prestado la crítica a la Canción de Crisóstomo — boca de oro-, aunque, como dice Mary Gaylord (2001) con razón, se ha atendido más a la valoración ideológica del suicidio de Crisóstomo ${ }^{17}$ y a la defensa por Marcela de su autonomía personal que al poema en sí, que es lo que nos interesa. Ambrosio está a punto de entregar al fuego - en el que ya estará acaso el suicida - los papeles que Crisóstomo le entregó, pero Vivaldo salva algunos de los que lee el que contiene la canción, epitafio de Crisóstomo y testimonio perpetuo de la crueldad de Marcela. Se trata de una canción que consta de ocho estancias y un envío endecasilábicos - lo habitual era combinar versos de siete y once-, de rima más veces rica que pobre, y con una rima interna además entre el penúltimo y el último versos.

16. Pero véase el comentario de Javier Blasco en la ed. de F. Rico, Vol. Compl., pág. 43.

17. La tradición del desesperado es más italiana que española. Como curiosidad, un poema de Vico, ya en pleno siglo XVIII, se titula Affetti di un disperato, y la ópera italiana del Renacimiento se recrea en figuras como Orfeo - Monteverdi - o Ariadna. Pero véase A. Alonso (2008) para el rastreo de una estética de la disonancia de fuentes diversas, italianas y españolas, que habría cristalizado en la canción cervantina. 
La voz de Grisóstomo surge del papel por dar gusto según él a Marcelauna Marcela imaginaria que é ${ }^{18}$ ha moldeado-, porque quiere ver publicada su crueldad, manifiesta en la muerte del pastor. Con ello, se convierten los versos en anuncio que, cuando se haga público, ya se habrá cumplido; aunque hay un margen para la ambigüedad, pues finalmente los destinó al fuego. Por otra parte, las palabras son inseparables del "son doliente" en el que irán mezcladas "pedazos de las míseras entrañas", no "concertado son" sino "ruïdo", término este todavía subrayado por la diéresis. Así que junto a la expresión lingüística, que puede quedarse corta, hay otro aspecto, el físico, que no puede engañar porque es don del mismo infierno (contra las acostumbradas invocaciones poéticas a la musa).

La segunda estancia enumera de forma cáotica animales y fuerzas de la naturaleza, junto con de nuevo las fuerzas del infierno, para hacer de su voz confusión, único modo de estar a la altura de "la pena cruel que en mí se halla", en eco probable de Garcilaso: "el desigual sentir no admite modo". La tercera estancia prosigue negando cualquier espacio civilizado para sus palabras - muerta ya su voz: él mismo - con lo que tendrá el raro privilegio de que los "ecos roncos" 19 de su mal se difundan pese a sonar en lugar desierto.

La cuarta estancia contiene la paradójica definición de su propia vida: "celoso, ausente, desdeñado y cierto/ de las sospechas que me tienen muerto" y por fin el calificativo "desesperado" que explica que, lejos de buscar esperanza, "estar sin ella eternamente juro", con lo que muy bien puede referirse a las penas que merece el suicida. La quinta estancia repite los motivos de la anterior, pero concretando en los celos y su consecuencia, el desdén, y recurriendo al modo interrogativo, para concluir pidiendo de forma explícita "un hierro" o "una torcida soga".

Por fin, en la quinta estancia se ve muriendo y pertinaz en su "fantasía": la de reafirmarse en la fe amorosa, desmentida en la estrofa anterior, hasta de nuevo desembocar en el "duro lazo" y la condenación eterna. Y en la sexta invoca a su enemiga para que ni por un momento se compadezca o turbe ante su muerte, antes bien para que se ría en la "ocasión funesta". Esta estancia hace eco a la segunda en que, como la segunda a la primera, sigue a una previa que se dirige a Marcela, y en que llama en confusión a los condenados del infierno clásico y al mismo Cerbero: sólo ellos pueden cantar las exequias al cuerpo de un suicida; sólo este último llevarles el contrapunto.

El envío invita a la propia canción a no quejarse, ya que existe gracias a la desgracia de Grisóstomo, y ya que la causa de ésta, Marcela, "con mi desdicha aumenta su ventura".

18. G. Serés (1996: 305) ve en ella una culminación de Galatea, y subraya la oposición cervantina a la pérdida del propio ser, de la autonomía personal, a causa del amor, contra la tradición de la lírica amorosa.

19. Adjetivo este que prodiga la obra cervantina, desde la voz "ronquilla" de don Quijote hasta el "ronco son" de los instrumentos que acompañan la aparición que anunciará en la segunda parte el modo del desencanto de Dulcinea. 
Todo lector del Quijote sabe que la verdad de Grisóstomo no es la verdad, que el narrador se encarga de poner en cuestión su versión inmediatamente y la propia Marcela de refutarla, tras aparecer de improviso — maravillosa visión-, para ser a su vez dejada en entredicho por el epitafio de Ambrosio. Éste, una octavilla, vuelve al tópico de la "esquiva hermosa ingrata" y la "tiranía de amor". Ambrosio se reafirma, pues, en la ideología que ha llevado a la muerte a Grisóstomo, como don Quijote apoya la autodeterminación de Marcela en tanto que encarnación misma y única del valor de la honestidad, aquél que regía en la edad de oro, un don Quijote que esta vez a nadie parece ridículo. Pero volvamos a la canción de Grisóstomo. Se ha hablado a su propósito de "narcisismo" y "autoelegía” (Souvirón, 1996), toda vez que se trata de otro epitafio en el que se reafirma Grisóstomo en su propia posición, entre el masoquismo y la pertinacia, con lo que muestra los límites de la ideología amorosa de que participa y el desastrado final a que conduce. Para ello es ayuda eficaz la inestabilidad entre el infierno clásico, al que se invoca de forma expresa, y las penas del cristiano, que se dejan entrever desde el momento mismo en que el fuego iba a ser el destino de la canción. Mary Gaylord (2001) llama la atención más bien sobre el aspecto metapoético, en otras palabras, la enorme atención que presta a definir la propia voz, la entonación adecuada a las materias a las que da forma. Pues, ¿se podría expresar fría y racionalmente un estado de ánimo que lleva al suicidio? Y en efecto, si algo llama la atención del lector es el énfasis y desmesura eficazmente buscados a lo largo del poema. Que, como afirma Gaylord, premia con la inmortalidad - ya que no con la salvación eterna- la determinación de Grisóstomo de alzar la voz; subraya el aspecto físico de ésta; atrae la sonoridad de la musa épica al ámbito lírico; y postula una difusión para la voz más allá de todo lo conocido. Y en definitiva propone una imagen de Grisóstomo como "sujeto moderno en el agónico momento de su auto-reconocimiento: entre silogismo y grito, entre razón y voz" ${ }^{20}$.

El último ejemplo de poema perteneciente al mundo pastoril es la letrilla de don Quijote (I, 26) escrita en coplas de arte real (dobles quintillas enlazadas por el estribillo "del Toboso"). Pero ahora estamos ante la versión, ya no realista ni experimental (que así se podría considerar la Canción desesperada) sino burlesca de ese mundo. Igual que Artidoro en La Galatea, don Quijote escribe versos en las cortezas de los árboles y en la arena (destinados, por tanto, a perderse), muchos versos de los que sólo se rescata la letrilla en cuestión, reída por todos precisamente por su estribillo identificador. A la risa sigue el narrador con una síntesis irónica del mundo pastoril y un quiebro final decididamente cómico: "Si como tardó tres días [Sancho] tardara tres semanas,

20. Así en M. Gaylord (2001: 298). A pesar del respeto que merece la figura de don Rafael Lapesa (1992), no creo que haya que entender de forma irónica la canción. Si se pudiera hablar de ironía, consistiría en todo caso en que el final de Grisóstomo se ve refutado por el comportamiento de los demás enamorados de la obra que entonan su propia muerte, al modo petrarquista, pero que acaban por tener éxito: Cardenio y don Luis. 
el Caballero de la Triste Figura quedara tan desfigurado que no le conociera la madre que lo parió" (I, 26). Sin embargo, lo cómico en el poema va más allá del estribillo, pues radica en que de las tres coplas, contrasta la primera quintilla, aceptablemente seria ${ }^{21}$, con la segunda, que, como varios sonetos preliminares, al rimar en —ote para poder introducir el nombre del amador, al recurrir a un léxico grotesco: "escote, estricote, pipote, cogote" produce efectos cómicos; hace rimar además Dulcinea con "ralea". Así que aplica los procedimientos de los poemas del marco al mundo pastoril.

7. Poemas amorosos. Los poemas del patetismo amoroso, esa estética que se centra en construir un héroe por su sentir, se distribuyen entre los que corresponden a la historia de Cardenio, los del "Curioso impertinente", y los que canta don Luis, caballeros los tres. Los de Cardenio son en total tres, dos de ellos sonetos. En I, 23, en el librillo de memoria de la maleta de Cardenio, al que aún no conocemos, lee don Quijote un soneto razonador que discurre mediante disyunciones y condicionales de estirpe cancioneril, para desembocar en la paradoja del primer terceto, y la certeza de muerte del segundo, que a diferencia del caso de Grisóstomo se verá desmentida por el decurso de la narración. Un soneto correcto $^{22}$ que puede relacionarse con el de I, 27, que no deja de merecer el equívoco de Sancho y la autoproclamación de don Quijote como poeta; seguirá la lectura de la carta misiva que ha merecido abundante atención crítica y desborda nuestro ámbito. Los versos de la letrilla de don Quijote contrastan con los de Cardenio, personaje ahora ya conocido, del principio de I, 27. Se cantan y les precede la reflexión de que los "pastores de voces estremadas, más son encarecimientos de poetas que verdades". Es el famoso ovillejo, forma al parecer inaugurada por Cervantes, de cerrada estructura anafórico-paralelística: las tres coplas arrancan con tres interrogaciones retóricas octosilábicas a las que el autor responde mediante trisílabos; las segundas mitades de cada copla, también relacionadas mediante anáfora, recogen en un argumento los términos diseminados en la primera. Reaparecen los tres elementos del autorretrato de Grisóstomo: desdeñado, celoso y ausente, hasta llegar al silogismo final, con su insistencia en la locura - aunque el Cardenio que canta es el cuerdo - lo que otra vez viene a refutar que el final de Grisóstomo fuera inevitable. "La hora, el tiempo, la soledad, la voz y la destreza" admiran a los oyentes ${ }^{23}$, por una vez no hay polemismo, e irían a buscar al músico, que les interrumpe al cantar ahora su

21. Aunque ya en la primera se hace rimar "plantas" con "tantas", tmesis según la edición de 1998 de F. Rico (p. 292 n. 15), y que podemos calificar simplemente de ripio. La nota citada desaparece en 2005.

22. Hice notar en 2001 que don Quijote alaba sin restricciones el soneto de Cardenio, pero es el juicio de un caballero andante, ridiculizado un momento después por el narrador (I, 26). Jauralde (1987-1988) destaca que don Quijote lo lee sin vacilar como expresión de una vivencia real, y que encanta a Sancho, por más que no entienda gran cosa: el prestigio de la palabra artística, en plena constitución de la literatura en sentido moderno.

23. La Galatea multiplica las ocasiones en que un pastor canta sin ser oído y es aplaudido por todos una vez que ha terminado. Pero aquí se ha empezado por refutar que la condición de pastor dé para tanto. 
soneto a la amistad (I, 27), el que Cernuda celebró por meditativo. Se basa en la contraposición entre la verdadera amistad huida al cielo, y su doble que ha quedado en tierra para engañar. Los tercetos repiten el apóstrofe del primer verso y resuelven mediante una disyunción excluyente: o verdad e imagen se reencuentran o el mundo se sumirá en el caos. Tras semejante énfasis, el canto se vuelve sollozos y ayes, y por fin cura y barbero oirán hablar a Cardenio.

El conjunto del "Curioso impertinente" se compone de cinco poemas, tres en I, 33 y dos sonetos en I, 34. Lotario argumenta contra las intenciones de Anselmo de convertirle en seductor de su mujer, y confirma el argumento de que una vez deshonrado de nada le servirá que nadie lo sepa con una octava real traducida de Tansillo (1510-1568). Sus cuatro últimos versos amplifican la idea de los cuatro primeros mediante la antonomasia "magnánimo pecho", y el subrayado de la soledad por la antítesis "cielo y tierra". Insiste poco después en el método de ilustrar con versos y recurre esta vez a tres redondillas de "una comedia moderna" ¿del propio Cervantes? Las dos primeras estrofas se apoyan en la tópica metáfora "es de vidro la mujer", la última en el mito de Dánae. Y todavía repite el procedimiento, esta vez el narrador, ¿citando? una copla de arte real construida al modo cancioneril por medio de paradojas paralelísticas, que se recogen en un concepto final: "Que, pues lo imposible pido,/ lo posible aún no me den". Concepto que parece rematar de loco e insensato a Anselmo. Más interesantes, pues no se limitan a lo meramente ilustrativo, son los sonetos de Lotario en I, 34. En plena situación de engaño a los ojos, con Camila a la mesa, Lotario recita ante ella y su marido un soneto supuestamente dedicado a Clori, pero en realidad a Camila. Es una libre imitación de los sonetos CCXVI o CCXXIII de Petrarca (la idea de ambos es similar): con el cíclico rodar del tiempo contrasta la persistencia del sufrimiento amoroso mediante la antítesis ("dulce sueño" frente a "pobre cuenta de mis ricos males"; la anáfora ("y.../ y..."); y el polisíndeton del último terceto que desemboca en verso bimembre "al cielo sordo, a Clori sin oídos". En una palabra, un buen ejemplo de la maniera de Petrarca, que introduce la problematización de la verdad: "Luego itodo aquello que los poetas enamorados dicen es verdad?" "En cuanto poetas, no la dicen [...]; mas en cuanto enamorados, siempre quedan tan cortos como verdaderos" (I, 34). Se diferencia así la verdad vivida de la enunciada.

El siguiente soneto, recitado a petición de Camila y que el propio Lotario valora menos que el anterior, constituye otro ejemplo de lo mismo en el que las ediciones hacen notar los ecos de Garcilaso. Tal vez la inferior valoración responda a su estructura menos perceptible. El primer cuarteto vuelve sobre la pertinacia del amante, antes muerto que arrepentido; el segundo - que contiene la estupenda expresión garcilasiana "podré yo verme en la región de olvido"- enfatiza mediante polisíndeton la misma idea, con la que enlaza el primer terceto. $\mathrm{Y}$ un epifonema ocupa el último terceto y contrasta por su forma exclamativa con todo lo anterior: advertencia del amante a sí mismo, inútil dada su porfía. 
Se cierra así lo que podríamos llamar el cancionero del "Curioso impertinente". Quedan aún dos ejemplos de poemas del patetismo lírico, los que "canta un mozo de mulas que de tal manera canta, que encanta" (I, 42: 547), mozo que no es otro que don Luis, como Clara descubrirá al punto. No deja de ser coherente que en una narración sentimental se inserten versos, aunque se vea entreverada de nuevas desventuras de don Quijote. Si es verdad la tesis citada de Chevalier, Cervantes se habrá divertido sorprendiendo al lector con que el mozo que canta en el género que, en efecto, va bien con su condición, acabe siendo "señor de lugares"; desde luego ambos poemas y el modo en que se cantan se celebran sin restricciones. Y hay que notar que en tema y estilo coinciden con los sonetos amorosos; contra quienes pretenden enfrentar los mundos poéticos del octosílabo y el endecasílabo, la estética resulta ser más determinante que la métrica.

El primero es un bello romance lírico, cuyo arranque - aparte de la reelaboración virgiliana notada por la crítica - comienza en la navegación sin rumbo, donde se quedó el último soneto de Lotario (I, 34). Pero aquí hay una estrella que guía al marinero. Todo el romance está montado sobre esa antítesis, hasta llegar a la invocación que juega con el nombre de doña Clara y el concepto en epanadiplosis final. Como ya notó Porqueras Mayo (1991), todo está vivo aquí, nada hay acartonado, y el romance sirve como presentación expresiva del enamorado joven, lo que viene reforzado por el hecho de que abre capítulo $^{24}$. Pero en plena confusión de Clara se oirá una nueva canción, ésta una oda en estrofas aliradas, a la que según parece había puesto música en 1591 don Salvador Luis, cantor de capilla de Felipe II. Forma un bello contrapunto con el romance anterior puesto que desarrolla el tema de la porfía amorosa, que, rompiendo a través de mil dificultades, es capaz de "alcanzar desde la tierra el cielo", donde opera de nuevo la asociación con la clara estrella que remató el romance. A diferencia de Grisóstomo, y al igual que el cautivo, don Luis no impone, sino que elige y da a elegir (D’Onofrio, 2001).

8. Poemas heroicos. Los dos últimos poemas del Quijote con entidad son los dos sonetos de la historia del cautivo (I, 40), dos epitafios que se pueden adscribir a la estética del patetismo, pero ya no del sentimentalismo amoroso sino del heroico. Como en el caso del romance de don Luis, el primer soneto abre capítulo en respuesta a la última frase de I, 39: "Y el de la Goleta decía así”; también como en el caso de don Luis se celebran: "Antes causarán gusto que pesadumbre", dice el cautivo antes de recitarlos (I, 39), y después de hacerlo, el narrador: "No parecieron mal los sonetos" (I, 40). Se da el caso de que si el cautivo recita el primero, el caballero el otro, lo que demuestra que suponen un ámbito poético común a ambos, en el sentido arriba aludido de poesía de clase, y en el más ligado a la trama que se descubrirá en el desenlace de la historia. Caracteriza a los dos sonetos el tono elevado, el movimiento temático ascensional, y el esquema de la victoria en la derrota que alrededor de veinte años antes había movido a Cervantes en la Numancia.

24. No podemos entrar aquí en el complicado problema de la "descolocación" del título de I, 43. 
9. En conclusión: 1605. Hasta aquí nuestro examen de la poesía inserta en el Quijote de 1605. Hemos visto que además de ser parodia de los libros de caballerías, la obra es en verdad un laboratorio en el que están presentes todos los géneros y estéticas de la época, y entre ellos los poéticos ${ }^{25}$. También la poesía, no cabe duda, muestra la fractura paródica de la que surgirá el realismo, dado que alternan los poemas serios con los burlescos, incluso en un mismo mundo poético tan importante para el autor como el pastoril. Puede verse éste como un conjunto de variaciones al que habría que sumar la Arcadia de 1615 , en la que ya no hay versos, sólo se mencionan (II, 68). Y en este primer Quijote, desde luego, parece haber un auténtico afán por demostrar que se es capaz de manejar los más variados metros y tópicos. Aunque ciñéndose a los movimientos de la narración, y así hay poemas que sirven de presentación de ciertos personajes, como don Luis; otros que caracterizan o explican, como la canción de Grisóstomo; otros que apoyan la argumentación, como los de Lotario; otros que elevan el tono, como corresponde a los del cautivo... Y hay que notar la elevada proporción de epitafios (a los que se puede sumar la Canción desesperada), así como el papel formador del romancero, al que ya nos hemos referido. Finalmente, apreciamos una preferencia por ciertos motivos temáticos de la poesía amorosa: la figura de la amada impresa en el pecho del amante, la navegación amorosa, y las variaciones líricas y narrativas sobre la muerte por amor.

10. En 1615... Examinemos ahora brevemente el Quijote de 1615. De entrada, ha desaparecido el marco; el número de poemas y fragmentos de Montero Reguera se eleva a 40 frente a 38 en 1605 (también el de alusiones romanceriles se eleva a 47 frente a 25); pero el de poemas completos originales, no fragmentarios, se reduce a 11, si las coplas cantadas en las bodas de Camacho se consideran un solo poema, que creo es lo correcto. La explicación que se suele dar es que la conciencia del género novelístico ha crecido en Cervantes $^{26}$. Lo que no impide que, si de fragmentos, ecos y reminiscencias se trata, aumenten, como han probado Puccini (1989) para los de Virgilio y Alonso Asenjo para el romancero. Al problema general de los romances ya nos hemos referido arriba. Baste añadir ahora que en la segunda parte inspiran episodios tan importantes y conocidos como el retablo de maese Pedro (II, 26); la cueva de Montesinos (II, 23); o la aparición de la duquesa Trifaldi (II, 38). Y que tres de los poemas originales de esta parte son romances: los que intercambian don Quijote y Altisidora en II, 44; II, 46; y II, 57. Quizá sea momento para insistir en que romancero nuevo y viejo aparecen también en la segunda parte realizando las mismas funciones y engendrando la misma

25. Que Cervantes haya aprovechado varios poemas compuestos con anterioridad al Quijote, sólo puede indicar un designio consciente.

26. Pero ya me referí en 2001 a que esa explicación presupone un género que precisamente estaba por nacer. Más probable me parece que opere también respecto de la poesía la conciencia autocrítica respecto de las digresiones - las narraciones intercaladas - de la primera parte, tal como se enuncia en II, 3. 
comicidad, y que si, a diferencia de lo que ocurría en 1605, es Sancho el que recurre ahora a ellos con más frecuencia, es porque ha ganado protagonismo.

11. Romances. Los ejemplos notables de romances cervantinos son los de Altisidora y don Quijote. Amorós (1981: 710) notó cómo alterna el autor lo serio y lo cómico en una serie que incluye el madrigal de don Quijote (II, 68) y las octavas reales (II, 69): "En tanto que en sí vuelve Altisidora". Monique Joly (1990: 137-138) se ha fijado en cambio en "cómo el eros caballeresco, al convertirse en motor de la conducta de don Quijote frente a cualquier 'dama', repercute por lo riguroso de las exigencias cervantinas en materia de decoro, en la caracterización de los personajes femeninos de la novela, y singularmente en su caracterización verbal". De todos los personajes, el que está a la altura es sin duda Altisidora, dotada de una iniciativa que sorprende incluso a los duques, y capaz de expresarse en la línea carnavalesca del mundo al revés: es una quinceañera, con nombre de vino, que supuestamente pretende a un cincuentón. Ella canta y encaja perfectamente su canto en la expectativa de don Quijote, que, cual Ulises cómico, ha determinado escuchar a la doncella atándose al recuerdo de Dulcinea. Y el romance, en efecto, empieza con el ofrecimiento de la doncella, que se dirige al "valeroso joven" deseando estar en su cama "rascándote la cabeza/ y matándote la caspa"; más aún quiere hacerle regalos de todo punto impropios, y no vacila en alabarse a sí misma de forma grotesca: "No soy renca ni soy coja", "los cabellos, como lirios"... "mis dientes de topacios". La crítica ha encontrado alusiones a la caballeresca, al Libro de Job, a Virgilio, a Garcilaso, y a varios romances viejos ${ }^{27}$. Y sabemos del "asombro de don Quijote y su reafirmación en el amor de Dulcinea, que el narrador rubrica sin piedad: 'Despechado y pesaroso como si le hubiera acontecido una gran desgracia'» (II, 68).

El caso es que don Quijote dará la réplica a Altisidora en II, 46, también mediante un romance. Amorós (1981: 711) destaca que este segundo es serio por completo, no así la ocasión - la incapacidad de don Quijote para percibir la burla - ni el desenlace: el temeroso escándalo cencerril y gatuno. El poema en sí es una reflexión de moral tradicional acerca del recogimiento y ocupación constantes adecuados a las doncellas, que reelabora el tópico filosófico de la impresión de la imagen de la amada en el alma del amante, para desembocar en la exaltación de la firmeza. El desenlace es conocido. Pero la cosa no quedará aquí puesto que todavía en II, 57, cuando ya don Quijote y Sancho, despidiéndose de los duques, recuperan la libertad, Altisidora "a deshora", esto es, sorprendiendo a los propios duques, canta "en son lastimero" un romance de despedida, que parodia el cuartetismo y uso de estribillos, lógicos en canto y danza, propios de los romances nuevos. Altisidora ${ }^{28}$

27. En concreto, A. González (1993: 614-615) cita Mira Nero de Tarpeya, La dama y el pastor, y el romance morisco Recoge la rienda un poco, entre otros ecos.

28. Cabe señalar posibles intenciones paródicas hacia el uso lopesco del romancero nuevo, en concreto el "De pechos en una torre" (R. Osuna, 1981); así como posibles ecos virgilianos (la despedida de Dido) u ovidianos (el lamento de Ariadna). Al fin, ambos coinciden en ser despedidas. En cuanto al estribillo, no deja de tener su gracia la asociación de los heterogéneos Vireno, Eneas, y Barrabás. 
empieza acusando al caballero de haberla burlado, pero, a diferencia de los dos anteriores, a continuación desciende a entrelazarse con la narración al acusarle de haber robado unas prendas íntimas, lo que contrasta con el contexto mitológico-burlesco (el mármol de Paro, Troya...); para volver a lo real: Sancho y su negativa a azotarse, y de nuevo lo burlesco: los juegos de naipes, los callos y las muelas. Lo serio se trivializa y lo cómico se solemniza, dice Osuna (1981: 102). También aquí se sabe que los circunstantes se admiran y don Quijote se queda sin respuesta, cosa rara en él, tanto como para dirigirse a Sancho y pasar a una discusión prosaica. Altisidora queda así como extremo en la desenvoltura — en la libertad — que se nota en sus acusaciones, atenuada tal vez por la elección del verso. Es este el único de los tres romances que se liga tan directamente al decurso narrativo como para hacer que se base este en discutir el asunto de las ligas anunciado en el romance. Desde luego, se trata de una mordacidad menos agresiva que la de Quevedo o Góngora, justamente por subordinarse a la línea narrativa general.

12. Poemas amorosos. Los poemas del patetismo amoroso son ahora el soneto del Caballero del Bosque (II, 12); y la glosa y la letrilla del hijo de don Diego de Miranda (II, 18). Es una cosecha más reducida que en 1605 (si se suman las redondillas cancioneriles de II, 38, y el madrigal de don Quijote de II, 68, hay que considerar que las primeras no son de Cervantes y que el madrigal es traducción).

"El soneto se ofrece", dice Jauralde (1987-1988: 35-36), "como verdadera poesía”, cantada por un caballero — todavía no sabemos que es Sansón Carrasco - aunque no sin cierto tono zumbón. En efecto, suena a Garcilaso -a petrarquismo: los contrarios, la imagen de la cera, de nuevo la impresión de la amada en el pecho del amante (Manero Sorolla, 1991: 770)_, pero lo que sorprende es que el mismo Cervantes que emplea la imagen eficazmente en el segundo soneto de Lotario (I, 33), lo haga ahora en otro en general bastante torpe. Con razón lo define la edición de Rico como "centón paródico de expresiones garcilasianas" (DQ II, 12: 789, n. 34), ratificado por el: "Con un ¡ay! arrancado, al parecer, de lo íntimo de su corazón”. Ya se sabe que a continuación el bachiller proclama la belleza de Casildea de Vandalia, lo que da pie a su lucha con don Quijote.

Los siguientes ejemplos son la letrilla y el soneto de don Lorenzo, hijo del interesante y controvertido personaje don Diego de Miranda ¿alternativa o no al ideal quijotesco? Según Canavaggio (2000: 197) el capítulo entero, que se abre con recuerdo expreso de Garcilaso - el "oh dulces prendas" aplicado con humor a las "tobosescas tinajas"-, manifiesta el entronque entre caballería andante y poesía. En medio del maravilloso silencio de la casa, después de comer, don Quijote, tras exponer las dificultades del género, pedirá a don Lorenzo que recite la glosa en que se viene ejercitando, y éste lo hace, en efecto, y se gana el aplauso entusiasta de su huésped.

Se basa en un mote ajeno (II, 18), cancioneril, y lo curioso es que, cuando don Quijote acaba de afirmar que la glosa no sufre hacer "nombres de verbos", el mote al menos se basa en ese recurso. Como más tarde en Quevedo — “soy 
un fue, un será y un es cansado"- aquí fue, es, será valen como antonomasias del pasado, presente y futuro para expresar el imposible deseo de que vuelva el pasado feliz o se alcance el futuro deseado ${ }^{29}$. La glosa (II, 18) está escrita en cuatro dobles quintillas octosilábicas enlazadas por el verso final, que vuelve al mote. Y cumple su cometido con virtuosismo, no hay aquí los versos "duros" que tanto se achacan a Cervantes, todo fluye, y las ideas se corresponden a la perfección con el mote. Se puede decir que su final constituye una nueva refutación de Grisóstomo.

Es difícil valorar la aparatosa aprobación de don Quijote, que de hecho halaga a don Lorenzo, por más que el narrador califique de loco al caballero. El caso es que le pide unos versos de arte mayor, y recita un soneto "a la fábula o historia de Píramo y Tisbe” (II, 18), que Márquez Villanueva calificó, con razón, de soneto de cerrado clasicismo y en la órbita garcilasiana ${ }^{30}$. De nuevo el poema parece completamente serio y conseguido. Se notará que el primer cuarteto vuelve sobre el pecho abierto del amante, motivo temático del soneto de Sansón Carrasco y del segundo de Lotario, citados. Se elabora el tópico del amor que vence imposibles (las almas que se juntan por la "quiebra estrecha y prodigiosa"), y en los tercetos, tras la desmesura que procura la muerte, la ejemplaridad condensada en una perfecta correlación trimembre, para la que se ha querido invocar el conocido soneto de Fernando de Acuña. Es una forma de vida más allá de la muerte. De nuevo don Quijote celebra los versos, y de nuevo estos son como corresponde a la calidad de su autor, tan diferente del bachiller Sansón Carrasco.

Ya al margen de la estética de lo amoroso, deberíamos recordar la seguidilla de II, 34 que canta el mancebito viajero, y que parece responder, de un lado, a que la poesía no sólo impregna el mundo cortesano sino el popular, y de otro, al gusto cervantino por el canto, que admiraba Cernuda y que se manifiesta sobre todo en las Ejemplares, además de en algunas comedias y en los Entremeses.

13. Versos ajenos. Vayamos ahora con los versos de autoría ajena. La Trifaldi, en II, 38, ilustra cómo le rindió la voluntad un caballero particular cantándole dos redondillas de tradición cancioneril, "De la dulce mi enemiga" y "Ven, muerte, tan escondida". Que el contexto narrativo es paródico es indudable: la Trifaldi se acuerda del platónico destierro de los poetas y de las "coplitas y estrambotes" y "seguidillas" más alegres y lascivos (que Sancho prohibirá en su ínsula); y de sus "trasnochados conceptos", sin dejar de men-

29. No consigo ver platonismo alguno, pese a la autoridad de Marasso, aducida en Vol. Compl. De la ed. de F. Rico, págs. 501-502 n. 847.37, en la concepción del tiempo del mote ni de la glosa; sí en cambio una intensa sensibilidad temporal para el presente de corte más bien agustiniano. ¿Se puede aplicar la imposibilidad de hacer retroceder el tiempo al deseo de don Quijote de que vuelva a haber caballeros andantes, enunciado hace un momento (Vol. Compl., pág. 140)? Nada en el texto lo refuta, pero tampoco lo apoya nada.

30. Apud Canavaggio (2000). Quiero recordar que es Juan de Arguijo el que más se ha recreado en escribir sonetos sobre mitos. El de Píramo y Tisbe, de todas formas, es tópico y lo sigue siendo durante el barroco, baste pensar en las versiones burlescas de Góngora. 
cionar las antítesis tan frecuentes en esta poesía - que el propio Cervantes, como sabemos, no deja de practicar cuando le conviene - aficionada a los "imposibles de esta ralea". Pero en último término "no me rindieron los versos, sino mi simplicidad, no me ablandaron las músicas, sino mi liviandad". He aquí un interesante ejemplo de condena aparente de la poesía para acabar salvándola.

En cuanto al "madrigalete" de don Quijote (II, 68), lo compone "en la memoria" y lo canta "al son de sus mesmos suspiros" mientras Sancho duerme a pierna suelta, pues "los pensamientos que dan lugar a coplas no deben de ser muchos". Don Quijote canta como caballero un madrigal que traduce otro del cardenal Pietro Bembo en Gli asolani, compuesto de tres estrofas que alternan versos de siete y once con rima consonante según el esquema del cuarteto. Percas de Ponsetti (1991: 119-120) confronta original y traducción para hacer ver que la de Cervantes es sumamente fiel. Y se pregunta si no confunde Cide Hamete cantar y suspirar al igual que no distingue hayas de alcornoques. No está claro una vez más lo que Cervantes se propone, si acaso, como dice Percas, que mientras que don Quijote toma en serio su poema, Cervantes no tanto (aunque, por cierto, demuestra su destreza como traductor, como si respondiera a la discusión habida en la imprenta de Barcelona) ${ }^{31}$.

14. Otros poemas. Los restantes poemas extensos del Quijote de 1615 son tres, el primero las coplas de II, 20. ¿Se puede hablar verdaderamente en este caso de poesía? Se trata de la "danza de artificio [...] de las que llaman habladas" de las bodas de Camacho, que consiste en unas figuras alegóricas con rótulos: Poesía, Discreción. Buen linaje, Valentía, Liberalidad, Dádiva, Tesoro, Posesión pacífica. Con semejantes nombres ya se entiende que prefiguran el desenlace del episodio. Cupido, el Interés, la Poesía y "de la parte del Interés" la Liberalidad, las cuatro figuras cantan sendas coplas — dobles quintillas - alusivas. Desde luego, no se sostienen por sí, son inseparables del espectáculo. Y el sentido de éste parece claro: el interés triunfa en primera instancia con su bolsón de oro, pero luego es el Amor el que rearma el castillo al que vuelve la doncella, encerrada como al principio; al igual que Basilio acabará por triunfar donde Camacho parecía inicialmente dueño de la situación. Sin que debamos olvidar que el bachiller que cuenta a don Quijote y Sancho la historia menciona a Píramo y Tisbe (II, 19), que habían inspirado el soneto de don Lorenzo en el capítulo anterior ${ }^{32}$.

El mismo carácter inseparable del espectáculo tienen los otros dos ejemplos poéticos a que arriba nos hemos referido. En II, 35, en plena mascarada nocturna, sobre un aparatoso carro triunfal, una "muerte viva, con voz algo dormida y con lengua no muy despierta" — desvela el narrador así algo del

31. En cuanto a lo problemático de que se cantasen las estrofas del Orlando de Ariosto, no cabe duda de que se cantaban, si hay que creer a Giraldi Cinthio en su Discorsi dei comporre romanzi.

32. ¿Justifica eso que aplique la edición de Rico (Vol. Compl., pág. 502) el concepto de mise en abyme a que apela A. Redondo (1991)? Desde luego, Redondo se está refiriendo a Basilio y al episodio en sí, pero no cabe duda de la anticipación culta del mito en II, 18, que ahora se traslada a lo pastoril. 
misterio - entona una serie de endecasílabos blancos en que se presenta como Merlín, un Merlín paradójico de condición “tierna, blanda y amorosa,/ y amiga de hacer bien a todas gentes", que apostrofa a don Quijote y revela el método para el desencanto de Dulcinea; así que el bien para ella es mal para Sancho, quien, aunque siempre antes ha asentido a las supuestas intervenciones del mago en los hechos de su amo, ahora se rebela y discute airadamente (López Navia, 1993: 260). Pero más que los versos en sí, en los que el endecasílabo blanco de epístolas y tragedias clasicistas contrasta con el contenido burlesco, importa el fantástico ambiente nocturno y la teatralidad general del episodio, autentica celebración del libro y de su autor en la que están concordes todos, desde los duques y la servidumbre hasta nosotros los lectores (Close, 1991: 483).

Parecido carácter tienen las dos octavas reales que canta "un hermoso mancebo vestido a lo romano" en II, 69, en el patio del palacio ducal. La primera de ellas, de Cervantes, recurre una vez más a la grotesca rima en - ote, y remata en el verso "con mejor plectro que el cantor de Tracia", Orfeo naturalmente, en eco del final del Quijote de 1605. La segunda estrofa reproduce la segunda de la Égloga III de Garcilaso. En el comentario correspondiente al lugar, M. Joly remite al momento del siguiente capítulo en que don Quijote pregunta al mancebo cantor "qué tienen que ver las estancias de Garcilaso con la muerte desta señora", por Altisidora, claro. El joven contesta con su condena de los poetas que hurtan, venga o no a cuento, y "no hay necedad que canten o escriban que no se atribuya a licencia poética" (II, 70). De modo que contrastan las octavas, necia e inspirada, como contrasta el auténtico Quijote con el de Avellaneda.

15 ¿Poesía en prosa? Una última cuestión nos queda por tratar. ¿Se reduce la palabra lírica a los poemas propiamente dichos, que además, como hemos visto, no siempre se pueden calificar de líricos? Pues Ynduráin (1985: 283) apunta que había en tiempos de Cervantes un "atisbo" de lo que hoy llamamos poesía en prosa. Y recuerda la discusión de la época acerca de tal posibilidad, por ejemplo, en el Pinciano. Lo que considera así son pasajes ricos en ornamentación retórica, por ejemplo, la carta de don Quijote a Dulcinea en Sierra Morena o la descripción de los ejércitos con los que confunde a las manadas de carneros. Apuntemos que se podrían considerar poesía en prosa en sentido más actual, más postromántico, otros momentos, como el que citó Gerardo Diego (1948: 227) de la descripción del túmulo de Altisidora muerta (II, 69): “Comenzó en esto a salir al parecer debajo del túmulo un son sumiso y agradable de flautas, que por no ser impedido de alguna humana voz, porque en aquel sitio el mesmo silencio guardaba silencio a sí mismo, se mostraba blando y amoroso". O, añadiríamos, la descripción nocturna previa a la aventura de los batanes: "Era la noche, como se ha dicho, escura, y ellos acertaron a entrar entre unos árboles altos, cuyas hojas, movidas del blando viento, hacían un temeroso y manso ruido, de manera que la soledad, el sitio, la escuridad, el ruido del agua con el susurro de las hojas, todo causaba horror 
y espanto" (II, 20). Y tantos otros, que enlazan con la discusión de Cervantes poeta no sólo cuando escribe en verso sino en el sentido más general.

16. En conclusión. Hemos visto que el Quijote de 1615 está tan impregnado de poesía como el de 1605, aunque en proporción diferente. Es verdaderamente otro mundo, que parece acompañar la evolución de la poesía cervantina tal como se aprecia en los Entremeses, las Comedias, y las Ejemplares. La presencia de los romances crece en alusiones y citas parciales, y en romances originales que representan o parodian los géneros del romancero nuevo, con un carácter entre irónico y burlesco menos violento que el de sus contemporáneos. El ámbito estético del patetismo sentimental, que no conoce fronteras entre el cancionero, los sonetos, y los romances, muestra preferencia por las tres imágenes o figuras ya mencionadas para 1605: la amada impresa en el pecho del amante; la muerte de amor, que en la práctica refuta siempre al Crisóstomo de DQ I; la navegación problemática. En cualquier caso, es un mundo poético que se contrae. A cambio de esa reducción, aparece el verso que forma parte integrante de la fiesta, como corresponde a la superior teatralidad de la obra.

¿Cuánto de juego y cuánto de seriedad hay en este proceder poético cervantino? Hay desde luego un manierismo serio, que se expresa mediante géneros diversos, pero también un narrador que tiende a ironizar al respecto, con variantes que van de la burla abierta a la sonrisa, entreveradas por la defensa de sí mismo como poeta. Y desde luego el principio del decoro sigue rigiendo la inserción de poemas, su calidad, y las reacciones que suscitan: baste comparar el soneto de Sansón Carrasco con los poemas de don Lorenzo. Como quiera que sea, si se repasa el conjunto de la primera y la segunda parte del Quijote, se comprueba que Cervantes, en su renovación y diálogo crítico con los géneros de la época, incluyó ampliamente los poéticos, y tanto en su versión culta, en la que siempre reverenció a Garcilaso además de no ignorar a latinos e italianos, como en la cancioneril y romanceril y en la popular.

\section{BIBLIOGRAFÍA}

Alonso, A. (2008). “La Canción desesperada de Cervantes: cancioneros, modelos italianos y sensibilidad romántica", en Juan Matas Caballero y José María Balcells Doménech (eds.), Cervantes y su tiempo. León: Universidad de León, Anejo I de Lectura y signo, vol. I, pp. 109-121.

Alonso Asenjo, J. (2000). “Quijote y romances. Uso y funciones” en R. Beltrán, Historia, reescritura y pervivencia del Romancero. Estudios en memoria de Amelia García Valdecasas. Universidad de Valencia, pp. 63-65.

Altamirano, Magdalena (1997). "El Romancero en la primera parte del Quijote", Nueva Revista de Filología Hispánica. XLV, pp. 321-336.

Amorós, Andrés (1981). "Los poemas en el Quijote", en Manuel Criado de Val (ed.), Cervantes: su obra y su mundo. Actas del I Congreso Internacional sobre Cervantes. Madrid: Edi-6, 1981, pp. 707-715. 
Bajtin, Mijail (1989). Teoría y estética de la novela (trad. esp. de H. Kriúkova y V. Cazcarra). Madrid: Taurus.

Beltrán, L. (2002). La imaginación literaria. Barcelona: Montesinos.

Canavaggio, Jean (2000). Cervantes, entre vida y creación. Alcalá de Henares: Centro de Estudios Cervantinos.

Cervantes, Miguel de (1973-1981). Poesías Completas, dos vols., Vicente Gaos (ed.). Madrid: Castalia.

Cervantes, Miguel de (1993). Obra Completa I, F. Sevilla y A. Rey Hazas (eds.). Alcalá de Henares: Centro de Estudios Cervantinos.

Cervantes, Miguel de (2005). Don Quijote de la Mancha, F. Rico (ed.) en dos volúmenes. Madrid: Círculo de Lectores/ Galaxia Gutemberg y Centro para la Edición de los Clásicos Españoles.

Chevalier, Maxime (1990). "Cervantes frente a los romances viejos", Voz y Letra. I, pp. 191-196.

Claube, J. (seudónimo de José Manuel Blecua) (1947). "La poesía lírica de Cervantes", Cuadernos de Ínsula I. Homenaje a Cervantes, pp. 151-187; también publicado en Sobre poesía de la Edad de Oro, Madrid: Gredos, 1970, pp. 161-195

Close, Anthony (1991). "Fiestas palaciegas en la Segunda parte del Quijote", en Actas del II Congreso Internacional de la Asociación de Cervantistas. Barcelona: Anthropos, pp. 475-484.

Diego, Gerardo (1948). "Cervantes y la poesía", Revista de Filología Española. XXXII, pp. 213-236.

D’Onofrio, J. (2001). “'Amorosas porfías/ tal vez alcanzan imposibles cosas' (I, 43). Sobre la voluntad y el libre albedrío en las últimas historias intercaladas del Quijote de 1605", en A. Parodi y J. D. Vila (eds.), Para leer el Quijote. Buenos Aires: Eudeba, pp. 87-101.

Eisenberg, Daniel (1987). A Study of Don Quixote. Juan de la Cuesta: Newark, 1987.

Fernández García, L. (2001). "La primera parte del Quijote como fuente de cancioneros: nuevos datos sobre el éxito y la recepción del texto", en A. Villar Lecumberri (ed). Cervantes en Italia. Actas del X Congreso Internacional de la Asociación de Cervantistas. Palma de Mallorca, pp. 93-106.

Garrote Bernal, Gaspar (1996). "Intertextualidad poética y funciones de la poesía en el Quijote”, Dicenda. Cuadernos de Filología Hispánica. 14, pp. 113-127.

Gaylord, Mary (2001). "Voces y razones en la Canción Desesperada de Crisóstomo", en I. Lozano y J. C. Mercado (coords), Silva. Studia philologica in honorem IsaíasLerner. Madrid: Castalia, pp. 287-300.

González, Aurelio (1993). "Cervantes y los temas del Romancero nuevo", en Actas del III Congreso Internacional de la Asociación de Cervantistas. Barcelona: Anthropos, pp. 609-616.

Jauralde Pou, Pablo (1987-1988). "Producción y transmisión de la obra literaria en el Quijote", Anales Cervantinos. XXV-XXVI, pp. 23-50.

Joly, Monique (1990). "El erotismo en el Quijote: la voz femenina", Edad de Oro. IX, pp. 137-148.

Menéndez Pelayo, Marcelino (1941). "Cervantes considerado como poeta", en Obras Completas (Estudios y discursos de crítica histórica y literaria I), vol. VI. Santander y Madrid: CSIC, pp. 258-268

Lapesa, Rafael (1992). "La descendencia hispano-portuguesa de una canción petrarquesca: de Garcilaso a Camoens y Cervantes", en Homenaje a Alonso Zamora Vicente III-2. Madrid: Castalia, pp. 131-147.

Lara Garrido, José (1987). Alonso Álvarez de Soria, ruiseñor del hampa. Torremolinos: Revista Litoral. 
Lara Garrido, José (1997). Del Siglo de Oro (métodos y relecciones). Madrid: Universidad Europea-CEES Ediciones.

Laskier Martin, Adrienne (1990). "Un modelo para el humor poético cervantino: los sonetos burlescos del Quijote", en Actas del I Congreso Internacional de la Asociación de Cervantistas, Barcelona: Anthropos, pp. 349-356.

López Navia, Santiago (1993). "El tratamiento paródico de la historia trascendente", en Actas del III Congreso Internacional de la Asociación de Cervantistas. Barcelona: Anthropos, pp. 251-263.

Lozano Renieblas, Isabel (1998). Cervantes y el mundo del Persiles. Alcalá de Henares, CEC.

Luján Atienza, Ángel Luis (2008). "La poesía inserta en el Quijote. Aspectos pragmáticos", en El Quijote y el pensamiento teórico-literario. Actas del Congreso Internacional celebrado en Madrid los días del 20 al 24 de junio de 2005. Madrid: CSIC, pp. 201-212.

Manero Sorolla, Pilar (1991). "Aproximaciones al estudio del petrarquismo en la poesía de Cervantes: La configuración imaginística del amante", en Actas del II Congreso Internacional de la Asociación de Cervantistas. Barcelona: Anthropos, pp. 755-779.

Márquez Villanueva, Francisco (1987). "El mundo literario de los Académicos de la Argamasilla", La Torre (Nueva época). I, pp. 9-43

Martín Morán, José Manuel (1997). "Cervantes: el juglar zurdo de la era Gutenberg", Cervantes, XVII, 1. pp. 122-145.

Martínez Bonati, Félix (1994). Don Quixote and the Poetics of the Novel. Cornell University Press: Ithaca.

Montero Reguera, José (1999). "Una amistad truncada: sobre Lope de Vega y Cervantes (Esbozo de una compleja relación)", Anales del Instituto de Estudios Madrileños. XXXIX, pp. 313-336.

Montero Reguera, José (2004). "'Poeta ilustre o al menos manifico", Anales Cervantinos. XXXVI, pp. 37-56.

Montero Reguera, José (2011). "Heterododoxias poéticas cervantinas. (Prolegómenos para una edición crítica de la poesía de Miguel de Cervantes", en Carmen Rivero Iglesias (ed.), Ortodoxia y heterodoxia en Cervantes, Alcalá de Henares: Asociación de Cervantistas/CEC, pp. 245-273.

Montero Reguera, José (2011b). "Trayectoria del epitafio en la poesía cervantina", en Visiones y revisiones cervantinas. Actas selectas del VII Congreso Internacional de la Asociación de Cervantistas, C. Strosetzki (ed.). Alcalá de Henares: Asociación de Cervantistas/CEC, pp. 629-639.

Osuna, Rafael (1981). "Una parodia cervantina de un romance de Lope", Hispanic Review. XLIX, pp. 87-105.

Percas de Ponsetti, Helena (1991). "Cervantes y su sentido de la lengua: traducción", en Actas del II Congreso Internacional de la Asociación de Cervantistas. Barcelona: Anthropos, pp. 111-122.

Porqueras Mayo, Alberto (1991). "Cervantes y la teoría poética", en Actas del II Congreso Internacional de la Asociación de Cervantistas. Barcelona: Anthropos, pp. 83-98.

Puccini, Darío (1989). "Virgilio en Cervantes (o el uso paródico y novelesco de un modelo clásico", Cuadernos Hispanoamericanos. CDLXVI, pp. 121-129.

Ramírez, Pedro (1995). "La lírica cervantina en su contexto narrativo", Versants: Revue Suisse des Littératures Romanes. 27, pp. 67-86,

Redondo, Agustín (1991). "Parodia, creación cervantina y transgresión ideológica", en Actas del II Congreso Internacional de la Asociación de Cervantistas. Barcelona: Anthropos, pp. 135-148. 
Rico, Francisco (1997). “'Metafísico estáis' (y el sentido de los clásicos)”, Boletín de la Real Academia Española. LXXVII, pp. 141-164.

Riley, Edward (1973). "Teoría Literaria”, en J. B. Avalle-Arce y E. C. Riley (eds.), Suma Cervantina. Támesis: Londres, pp. 293-322.

Rivers, E. L. (1983). "Cervantes y Garcilaso", en Homenaje a José Manuel Blecua. Madrid: Gredos, pp. 565-570.

Rojas, Ricardo (1916). "De Cervantes considerado como poeta lírico", prólogo a Poesías de Cervantes. Buenos Aires: Universidad Nacional de la Plata, 1916.

Romo, Fernando (2001). "Cervantes ante la palabra lírica”, en A. Bernat (ed.), Actas del IV Congreso Internacional de la Asociación de Cervantistas. Universitat de les Illes Balears: Palma de Mallorca, pp. 1063-1088.

Serés, Guillermo (1996). La transformación de los amantes. Imágenes del amor de la Antigüedad al Siglo de Oro. Barcelona: Crítica.

Souvirón, B. (1996). "La canción desesperada. Del narcisismo a la autoelegía", Revista de Filología Española. LXXVI [3-4], pp. 317-325.

Ullman, P. L. (1961-1962). "The Burlesque Poems Which Frame the Quixote", Anales Cervantinos. IX, pp. 213-227.

Vega Ramos, M José, Esteve, Cesc (eds.) (2004). Idea de la lírica en el Renacimiento (entre Italia y España). Vilagarcía de Arousa: Mirabel, 2004.

Ynduráin, Francisco (1985). "La poesía de Cervantes: aproximaciones", Edad de Oro, IV, pp. 211-235.

Recibido: 11 de abril de 2011

Aceptado: 15 de enero de 2013

Resumen: Este artículo examina los poemas líricos incluidos en la primera y la segunda parte del Quijote. Las diferentes clases de poemas se estudian en su contexto narrativo, pero se estudian también en relación con categorías métricas y estéticas como realismo, parodia, manierismo...

Palabras clave: poesía, contexto, soneto, romance, estética, realismo, parodia, manierismo.

Title: Cervantes and the Lirical Poetry: Don Quixote

Abstract: This essay examines the lyrical poems included in the first and the second part of Don Quixote. The different classes of poems are studied attending to its narrative context. But the poetry is also studied by relating it with metrical and aesthetical categories: Realism, Parody, Manierism...

Key Words: poetry, context, sonnet, "romance", aesthetics, realism, parody, manierism. 